Comunicação "Portugal perante as nações: António Ferro e a imagem do país" apresentada no I Colóquio Internacional «Construção de identidade(s). Globalização e fronteiras», realizado a 11 de Novembro de 2011, pelo CITCEM (Centro de Investigação Transdisciplinar, Cultura, espaço e memória), na Faculdade de Letras da Universidade do Porto. 
Portugal perante as nações: António Ferro e a imagem do país.

A presente comunicação resulta de um ano de e investigação no doutoramento em História, na FLUP, pelo que a visão aqui apresentada é necessariamente parcial, uma vez que ainda não está terminada, e os dados revelados provisórios.

Num colóquio subordinado ao tema da construção da identidade, parece apenas apropriado falar da construção identitária nacional, num período tão especial como foram as duas primeiras décadas do Estado Novo, levando em consideração que a consolidação da ideia de Nação foi o centro da política cultural deste regime.

Benedict Anderson defende que "o factor nacional é o mais universalmente legitimado entre os valores da vida política do nosso tempo (2005: 22).

A Nação, fenómeno da modernidade, apresenta-se como uma forma de identidade colectiva, que apela a um discurso assente na unidade, originalidade e diferença. Encarando-a, não como uma realidade natural, mas como um processo de "engenharia cultural", na expressão de Ernest Gellner, deparamo-nos com o fenómeno da "tradição inventada" - tradições construídas e institucionalizadas formalmente, práticas normalmente reguladas por regras, tácita ou abertamente aceites, de natureza ritual ou simbólica, que visam inculcar certos valores e normas de comportamento através da repetição, o que implica, necessariamente, uma continuidade em relação ao passado, mas um "passado historicamente apropriado" (HOBSBAWM, RANGER, 1997: 9). Assim, a História é utilizada como legitimadora das acções e como "cimento da coesão grupal", sendo que "não corresponde ao que foi realmente conservado na memória popular, mas àquilo que foi seleccionado, escrito, descrito, popularizado e institucionalizado por quem estava então encarregado de fazê-Io" (HOBSBAWM, RANGER, 1997: 21).

Trata-se, acima de tudo, de elementos com forte carga simbólica e emocional, que funcionam como instrumentos de identidade e coesão social e nacional. Assim, e no que concerne ao processo de construção e afirmação da Nação e da identidade nacional, torna-se necessário conferir atenção aos aspectos de adesão emocional à ideia nacional, elementos de que fala Löfgren: "The common national memories and understandings are sometimes more strongly articulated in non-verbal forms, in shared smells, sounds, tastes and visions" (1989: 12) e a que Raymond Williams deu o 
nome de "structure of fellings", sendo que, neste sentido, algumas sensações são mais nacionais do que outras, isto é, detêm um maior poder/carga simbólica.

As diferentes identidades nacionais apresentam como traço comum a procura e a (re)invenção de uma cultura própria, assente em mitos/crenças de antiguidade da Nação e das suas origens remotas. Para fortificar estas identidades nacionais, torna-se necessário a descoberta dos próprios países: a sua história, os seus heróis, as suas paisagens. Acima de tudo, para reencontrar os fundamentos da Nação, torna-se fundamental regressar ao povo e à sua cultura, encarado como o "fóssil vivo desses primeiros antepassados" (ROSMANINHO, 2010: 521).

Neste sentido, o estudo e a celebração das tradições populares, da cultura do Povo, assumidas pelos diferentes nacionalismos como fundamento da Nação, desenvolve-se um pouco por toda a Europa ao longo dos séculos XIX e XX. Com efeito, parece existir uma relação simbiótica entre ambos, uma vez que a ideologia nacionalista conduz com frequência à exaltação de costumes antigos (ou que se crê serem antigos), reveladores (supostamente) de um carácter único e distinto, legitimando, por consequência, a nacionalidade: “A vida das nações europeias começa com a designação dos seus antepassados e com a proclamação de uma descoberta: existe um caminho de acesso às origens" (THIESSE, 2000: 25).

Nesta redescoberta do popular, operada no sentido que Herder Ihe conferiu, isto é, da procura do "génio nacional" ou do "carácter nacional", os modos de pensar, agir e de comunicar peculiares e únicos de cada Nação, é de destacar a clara redução do popular ao rural: o povo de que se fala e que se estuda não é o mundo popular no seu todo, mas os camponeses detentores de costumes intocados por estrangeiros, próximos de uma natureza purificada e purificadora, que se percepcionam como a alma da Nação, o génio ancestral, símbolo da pátria e referente étnico que prova que, apesar de todas as mudanças, esta permanece imutável.

Autores como Orvar Löfgren destacam a importância do espaço exterior nos processos de construção da Nação: "In order to create a symbolic commmunity, identity markers have to be created within the national arena in order to achieve a sense of belonging and loyalty to the national project, but this identity also has to be marked to the outside world as national otherness" (1989: 9). Com efeito, a ideia da Nação, assente na questão das fronteiras simbólicas, pressupõe a existência de outras 
nações, decisivas na edificação da consciência identitária - a especificidade da identidade nacional estaria dependente da aprovação, real ou imaginada, enquanto alteridade nacional, por parte de outras nações.

É neste contexto que se inserem as exposições internacionais, que surgem a partir de meados do século XIX: nascidas em consequência do desenvolvimento da produção da indústria mecanizada, focadas essencialmente no progresso industrial, num mundo dominado pela aplicação das máquinas ao trabalho e ao quotidiano humano e pela fé na capacidade do génio humano, constituem um retrato da sociedade burguesa que se formara, consolidara e, enfim, dominava um pouco por toda a Europa, verdadeiras operações de propaganda dos governos dos países organizadores, palcos de exibição identitária nacional por excelência. Assim, sob uma capa de mostra do progresso e modernidade das nações, verifica-se na realidade uma cada vez mais acesa rivalidade entre Estados, a nível do progresso económico e tecnológico, mas também no que à cultura nacional diz respeito. Neste sentido, as exposições internacionais reflectem um processo de auto-representação/auto-criação dos Estados-nações.

A exibição das tradições populares nacionais tornou-se, assim, num dos aspectos mais em destaque nestes eventos, pelo menos até meados do século XX, por duas razões fundamentais: primeiramente, o menor desenvolvimento económico de certos países justificaria o investimento nesta área, e, depois, aquilo que parecia atrair mais visitantes era, exactamente, o exotismo da cultura popular. Ganham então primazia os artefactos e objectos artísticos provenientes do mundo rural, graças à espectacularidade que este tipo de cultura material podia conceder à Nação, e ao facto de The conferir um carácter mais tangível. Com efeito, para provar "a peculiar historically rooted and aesthetically valuable national culture" (STOKLUND, 1999: 6), numa mostra essencialmente visual como eram estas exposições, a cultura imaterial de pouco servia "and therefore material folk culture was more suitable for that purpose - and especially such material elements that at the same time were aesthetically appealing: folk costumes and other textiles, vernacular architecture and rooms in the peasant house with richly decorated furniture and implements" (STOKLUND, 1999: 7). 
Em Portugal, durante o período do Estado Novo, verificou-se igualmente uma clara necessidade de (re)criação da imagem do país. Uma das principais atribuições do organismo criado pela Presidência do Conselho, através do Decreto-lei no 23 054, datado de 25 de Setembro de 1933 - o Secretariado de Propaganda Nacional (SPN) ${ }^{1}$ era a propaganda do país: "Compete ao Secretariado, em matéria de informação, promover no País e no estrangeiro a divulgação e a exacta compreensão dos factos mais importantes da vida portuguesa" (SNI, 1955: 11). António Ferro, director entre 1933 e 1949 do SPN, reconhece claramente que a Nação não existe sem ser por via da projecção, percebendo desde muito cedo a potencialidade a este nível dos eventos internacionais, quando afirma: "Não serão todas as exposições internacionais admiráveis campanhas de propaganda nacional?" (1949: 21).

Desta forma, a renovada imagética do país é concebida, nos primórdios do regime, por este homem, que Paulo Pina vê como "portador dum projecto global de difusão da imagem do país" (1988: 89) e que Margarida Acciaiuoli percepciona como "o pintor oficial" do regime: "Os traços e as cores com que o valorizou adoçaram-lhe os contornos, deram-Ihe um verniz cosmopolita e emprestaram-Ihe uma abertura modernizadora que realmente não tinha" (1991: 487-488).

Desde cedo que Ferro parece ter-se inquietado com a falta de projecção da imagem de Portugal no mundo. Assim, em 1929, ao deparar-se com o Pueblo Español na Exposição Internacional de Barcelona, desabafa: "O mundo não nos conhece. Precisamos, antes de mais nada, dar-Ihe o nosso retrato, oferecer-lhe a nossa casa: estender-Ihe uma cadeira e um tapete, abrir-lhe uma janela, trazê-lo para a nossa lareira... O 'Pueblo Español'é uma lição formidável deste nacionalismo bem compreendido" ${ }^{2}$. Em 1932, num artigo publicado no Diário de Notícias, o futuro director do Secretariado volta ao assunto, lamentando a falta de notoriedade de Portugal, em contraste com outros países: "Actualidades americanas, inglesas, francesas, alemãs, russas, espanholas, romenas, belgas, jugo-eslavas, checas....Nunca ou quasi nunca uma actualidade portuguesa, quer no claro-escuro do cinema, quer na retrogravura sépia dos magazines europeus"; conclui afirmando: "Portugal, isolado no

\footnotetext{
${ }^{1}$ Que se converte, em 1944, fruto da conjuntura internacional, em Secretariado Nacional de Informa ção, Cultura Popular e Turismo (SNI).

2 “Portugal em Barcelona”. Diário de Notícias, 04.06.1929, p. 1.
} 
seu mirante, não conseguiu ainda, apesar de toda a propaganda, impor-se à Europa e ao mundo" ${ }^{3}$.

Como salienta Vera Alves, "a sua vivência no estrangeiro torna-o consciente da importância das relações exteriores na afirmação do carácter distinto de determinada nação" (2007: 260).

A imagem de Portugal e do povo português criada pelo Secretariado, de acordo ainda com esta autora, inspirava-se em modelos de construção identitária que circulavam internacionalmente, com os quais Ferro teria contactado nas exposições internacionais que desde 1929 frequentava, e decorreria igualmente da influência exercida pela viagem de Ferro ao Brasil, em 1922, quando contacta com as teorias nativistas e com escritores como Mário e Oswald de Andrade, que defendiam a conjugação da estética de vanguarda com a busca das raízes que definiriam o que era ser brasileiro. É dentro deste quadro internacional que Ferro compreende o valor do uso do demótico e a receptividade intelectual a esta imagética popular, que "se transformara num símbolo de uma vida alternativa, alheada da industrialização massificadora" (ALVES, 2007: 255).

Esta demanda do popular pelo SPN concretiza aquilo a que se referia Orvar Löfgren, quando falava da nacionalização da cultura popular, algo que não se assume como um mero processo de invenção da tradição mas, antes, apropriação da cultura demótica, produzindo-se uma "versão correcta, autorizada e atemporal da vida popular [...] através de processos de seleç̧ão, classificação, relocalização e cristalização" (ALVES, 2007: 162).

Ora, os processos de selecção e depuração dos materiais da cultura popular de que aqui se fala foram moldados pela sensibilidade estética e moral dos grupos sociais mais favorecidos e cultos; com efeito, esta demanda do popular foi, na maioria dos países europeus onde ocorreu, de pendor fortemente elitista, realizada por grupos de intelectuais. No fundo, o que se verifica é o predomínio de "um conjunto de ideais estéticos exteriores às populações que produziam esses [...] objectos" (ALVES, 2007: 164).

\footnotetext{
3 “Vida”. Diário de Notícias, 07.05. 1932, p. 1.
} 
Esta escolha de objectos populares com forte poder decorativo enquadra-se no fenómeno de objectificação cultural de que fala Richard Handler: "Objectification refers to the tendency of Western logic to imagine nonmaterial phenomena [...] as if they were embodied, or existent as physical objects" (1984: 55). Ou seja, a objectificação cultural centra-se nos processos de selecção de uns elementos culturais à custa de outros, o seu aperfeiçoamento e reformulação, quando os elementos isolados são corporizados e retirados do contexto original - descontextualizados portanto - e posteriormente recontextualizados, conferindo-se-Ihes novos sentidos e significados, agora como signos da identidade nacional. Verifica-se, desta forma, um processo de (re)invenção cultural. Handler reporta-se, assim, à objectificação cultural como "a construction grounded in the ideology of the present" (1984: 62).

Neste sentido, a cultura popular apresenta-se como um elemento a ser nacionalizado, sacralizado até, usado como fonte da identidade nacional, em tempos remotos da existência da Nação, que o distinguem de forma clara das outras nações. Parece, pois, inevitável que "a correct, authorized and timeless version of folk life is produced through the process of selection, categorization, relocation and freezing" (LÖFGREN, 1989: 8).

No projecto de representação de Portugal no estrangeiro do director do SPN, objecto pois de objectificação e nacionalização cultural, torna-se necessário descortinar o que é criação de Ferro.

Sabemos que a imagética de potência colonial era uma condicionante do regime e da sua fundamentação ideológica e nacionalista, num discurso histórico legitimador das possessões e da política colonial encetada. Esta faceta de exibição da Nação vinha já do período anterior, uma vez que a 1a República tinha de forma sistemática participado nas variadas exposições internacionais então realizadas, em especial nas dedicadas em exclusivo à temática colonial. Portanto, a exibição das colónias e do império não era criação exclusiva de Ferro, antes parte de um arsenal de representações do país herdado de regimes anteriores.

A componente historicista esteve sempre presente; com efeito, não foi apenas o Estado Novo a conferir importância ideológica à História e a utilizá-la politicamente.

Estas serão, assim, estratégias que, sujeito aos constrangimentos das exigências do poder político, Ferro continuará a utilizar. Todavia, na aç̧ão de Ferro entra um 
novo elemento: a vontade de promoção de um povo antigo e moderno simultaneamente leva-o a basear o seu projecto identitário na arte popular, que "assumia uma vantagem em relação ao culto da história pátria: a de um instrumento de afirmação nacional que não falaria só do passado, mas também do presente" (ALVES, 2007: 268).

Esta escolha de Ferro releva de dois conjuntos poderosos de razões: por um lado, não podendo avançar com potência ou inovação, não podendo concorrer directamente com atracções de tipo mais erudito ou cosmopolita, o director do SPN transforma o atraso em arcaísmo autêntico e, portanto, prestigioso; por outro, a procura de um factor de diferenciação perante as outras nações, mais do que a competição directa, para a qual o país não possuía meios, aquilo que Paulo Pina designa de "igualar-se pela diferença" (1988: 97) e a que Ferro, no seu discurso de 1948, na inauguração do Museu de Arte Popular, faz referência: “A diferenciação é a própria independência dos povos, a profunda manifestação do seu carácter, seja qual for o aspecto em que se manifeste" (SNI, 1948: 13), e acrescenta: "Sejamos nós, sejamos diferentes, e seremos eternos!", uma vez que "só o diferente, o inédito, interessa e apaixona os outros povos", concluindo que "Portugal, na carta do globo, tem a sua cor e o seu desenho próprio, cor e desenho eterno" 4 .

Torna-se importante sublinhar, mais uma vez, que as suas opções enquanto director do organismo nacional de propaganda, de escolha das tradições rurais como idioma de afirmação externa de Portugal, embelezadas por uma estética modernizante, longe de serem uma escolha isolada do país, inserem-se antes num quadro europeu muito abrangente de elaboração da identidade nacional, provindo de meados do século XIX e com especial incidência nas décadas de 20 e 30 do século XX, tanto em Estados periféricos, como a Roménia ou a Suécia, como em países poderosos, como a França ou a Inglaterra, indo "ao encontro de uma sensibilidade generalizada em toda a Europa e em amplos círculos da sua intelectualidade" (ALVES, 2007: 13).

\footnotetext{
${ }^{4}$ Ocidente, no. 33, 12.1940, p. 322, 431 e 434.
} 
Esta imagética ruralizante, sustentada em especial na arte popular, era claramente uma construção elitista, revestida de uma nova estética modernizante e destinada a um olhar estrangeiro, às participações portuguesas em grandes exposições internacionais, através das secções de cultura e arte popular que se levam a Paris, à Exposição Internacional das Artes e Técnicas da Vida Moderna, em 1937 e, dois anos depois, à World's Fair de Nova Iorque, e a S. Francisco, à Golden Gate International Exposition, no mesmo ano. E assim, a participação em exposições internacionais remete para a necessidade de "mostrar a contribuição portuguesa para a civilização do mundo, a obra e o pensamento político do Estado Nacional, as realizações, os métodos e os ideais colonizadores portugueses, hoje e no passado (PAULO, 1994: 76), essencial num clima político tão conturbado como foram as décadas de 1930 e 1940.

A Exposição Internacional das Artes e Técnicas da Vida Moderna foi a oitava edição das exposições universais na cidade de Paris. Aberta a 25 de Maio e tendo encerrado a 25 de Novembro de 1937, contou com um pouco mais de 31 milhões de visitantes, 45 nações presentes, uma área de aproximadamente 105 hectares e uma superfície edificada de 9,5 hectares.

Oficialmente, o seu objectivo era "the elevation of taste through the arts and the improvement of everyday life by science through industry" (CHANDLER, 1990: 284). Como afirmou então o comissário-geral: “[A Exposição] reunirá obras originais dos artistas e industriais. Esforçar-se-á por mostrar que as realizações artísticas podem intervir nos mais modestos domínios, que não há nenhuma incompatibilidade entre o belo e o útil, que as Artes e as Técnicas devem estar indissoluvelmente ligadas, que o progresso natural se desenvolve sob o signo da arte" (OLIVEIRA, 1998: 26).

É o Decreto-lei de 27 de Junho de 1936 que determina e organiza a representação portuguesa na exposição parisiense de 1937, sob a fiscalização do Ministério dos Negócios Estrangeiros. Na Comissão Portuguesa, dentro da longa lista de participantes, destacam-se os nomes de António Ferro (nomeado comissário-geral), António Eça de Queirós (comissário-geral adjunto), Paulo Mendes Osório (chefe de gabinete de imprensa), Jorge Segurado (como delegado técnico), Francisco Keil do Amaral (arquitecto) e a equipa de decoradores, constituída por homens como Bernardo Marques, Fred Kradolfer, Carlos Botelho, Paulo Ferreira, Thomás de Mello (Tom), Emmérico Nunes; ainda, os escultores António Azevedo, Luís Fernandes, 
Henrique Bettencourt, Francisco Franco, Canto da Maya e Barata Feyo, e os pintores Jorge Barradas, António Lino, António Soares, Estela Faria, Eduardo Malta, Dórdio Gomes. Em resumo, uma equipa de artistas do SPN, homens e mulheres provenientes de duas gerações distintas do modernismo português.

Em Paris, Portugal procurou apresentar-se, não tanto como um país moderno, mas sim como uma pátria "onde o progresso (que se fez sentir, obviamente, desde 1926) não destruiu as heranças de uma cultura ancestral" (OLIVEIRA, 1998: 94). Procurava-se encenar uma identidade e singularidade nacionais, algo que inicialmente se mostrava como problemático, tendo em conta a própria temática da exposição: uma vez que Portugal tinha uma mitigada produção nas áreas das técnicas e das artes, vistas enquanto indicadores do desenvolvimento de uma Nação, Ferro sente a necessidade de adaptar, de fazer uma interpretação muito própria da divisa inerente à exposição; assim, a arte transformou-se nas "riquezas artísticas mais notáveis" e a técnica nos "principais produtos da indústria e do solo nacionais" (ACCIAIUOLI, 1998: 42).

Como já foi referido, o tratamento estado-novista concedido à arte popular foi, mais do que a redescoberta, uma requalificação, em bases modernizantes, da tradição, efectuada por um olhar proveniente das elites, e destinada às elites, neste caso as estrangeiras. Esta procura da conciliação entre o moderno e a tradição vê-se, desde logo, no próprio pavilhão português, uma estrutura modernizante e de superfícies lisas e depuradas, que valorizavam a função do edifício; a componente nacional era apresentada por um janelão onde se encontrava o escudo nacional e por uma arcaria cega tradicional, no corpo principal do edifício. Tratava-se de uma fórmula de "aportuguesamento" da gramática internacional então em voga, um pavilhão construído para ser "um grande cartaz de Portugal sobre o Sena" ${ }^{5}$.

A seç̧ão de "Arte Popular" apresentava uma notável colecção de bonecas, vestidas com trajes regionais de todas as províncias portuguesas, bem como inúmeros objectos de artesanato, ilustrando a variedade e complexidade do país, em trabalho de Thomás de Mello e Dalila Braga. Ferro apostou ainda numa faceta lúdica, integ rando

\footnotetext{
5 “O Pavilhão de Portugal na Exposição Interna cional de Paris de 1937". Revista Oficial do Sindicato Nacional de Arquitectos, nㅇ.. 1, 1938, p. 21.
} 
na representação nacional festas de sabor popular, com danças folclóricas, apresentadas no terraço do pavilhão. Destaca-se a Nuit Portugaise, a 28 de Junho, uma festa de danças em trajes regionais e canções populares, um evento que procurou transpor as festas populares de S. João e Santo António para o cosmopolita cenário parisiense, juntando folclore e turismo. O fado, cantado por Maria Albertina, acompanhada pelo guitarrista Armando Machado, ajudava a recriar o ambiente popular, para o mesmo contribuindo o facto de algumas das senhoras da delegação portuguesa se apresentaram vestidas com indumentárias regionais, como foi o caso de Fernanda de Castro, esposa de Ferro, que apareceu com um traje tradicional de saloia sintrense. Em 17 de Outubro, mais um espectáculo, desta feita a encerrar a participação nacional: a Gala Portugais, onde constava uma composição de música clássica que procurava a integração da música popular, de Ruy Coelho, e a Rapsodie Portugaise, conferência dialogada entre António Ferro e Fernanda de Castro, complementada por um conjunto de interpretações em canto e canto-dança, de sugestão folclórica, representando as diferentes regiões do país.

Expõe-se, portanto, uma imagem idílica, de um país pastoral, doce e virgiliano. Portugal parece ter conseguido afirmar a sua presença nesta parada de nações pelo tratamento artístico a que a nação foi sujeita, pela mão do director do Secretariado e da sua equipa de modernistas, de tal forma que se pode afirmar que "foi à margem da temática da exposição, mas paralelamente a ela, que se forjou a autêntica imagem do Estado Novo, no seu carácter de assumida 'modéstia' e de conversão em 'ordem', sinais identificadores da exemplaridade do 'Estado modelo' que um humanismo peculiar revestia agradando a certa crítica francesa que se limitou a assiná-la dentro destas noções" (ACCIAIUOLI, 1998: 62).

Dois anos depois, em Nova Iorque, realiza-se a World's Fair. Pensada oficialmente para festejar o 150 ㅇ aniversário dos Estados Unidos da América ${ }^{6}$, a Exposição Universal de Nova lorque contou com a presença de 54 nações, um número nunca alcançado neste tipo de iniciativas. Dedicada ao "Mundo do Amanhã", arquitectos e pintores tiveram como missão idealizar diferentes versões da América no

\footnotetext{
${ }^{6}$ A contagem fez-se considerando que a nação a mericana se formalizou quando George Washington tomou pos se como presidente em 1789.
} 
futuro. Um dos papéis mais importantes foi o assumido pelos designers industriais e por técnicos experientes em demonstrações de tipo efémero, que criaram maravilhas como o Voder (máquina falante que reproduzia a voz humana) ou o Rocketport (espécie de nave espacial onde se embarcava para um passeio simulado ao espaço, até ao planeta Marte). Na realidade, a exposição de Nova lorque apresentou toda uma série de invenções revolucionárias, marcando o aparecimento de produtos e tecnologias que, nas próximas décadas, fariam parte da vida moderna: a Radio Corporation of America fez a primeira grande transmissão televisiva em directo ${ }^{7}$; a General Electric Company apresentou os raios $\mathrm{X}$, ao permitir aos visitantes espreitarem o interior de uma múmia egípcia, escondida num sarcófago selado; a Chrysler Motors expôs o cinema a três dimensões, possibilitando aos espectadores, através do uso de óculos Polaroid, observarem imagens em relevo, a cores e em movimento, de partes de automóveis; a Eastman Kodak Company provou a sua liderança no campo da fotografia, ao exibir as novas técnicas de cor e de ampliação, através do Kodachrome. Em resumo, "saltos enormes para a tecnologia, as artes e os confortos humanos, colocados americanamente ao serviço do homem comum" (MARTINS, 1996: 47).

Ferro, novamente comissário-geral, prossegue na revelação de Portugal ao mundo, encarando-se a participação portuguesa como um grande objectivo nacional, colocando em relevo o papel dos portugueses na descoberta da América e, acima de tudo, contribuindo para demonstrar o ressurgimento nacional operado desde a implantação do Estado Novo.

Sendo o "Mundo do Amanhã" o eixo directriz da exposição, Ferro subverte-o, ao encenar um Portugal pleno de simplicidade de vida, de pureza de costumes, num equilíbrio das reacções sociais, contra a deificação da aparelhagem que diminuía o homem, contra o delírio mecânico, isto é, o ideário que modestamente tinha sido esboçado dois anos antes, em Paris.

Num canto da zona dos Governos, entre o Luxemburgo e a Roménia, virado para a Lagoa das Nações, estava o pavilhão português, a cargo do arquitecto Jorge Segurado, escolha de Ferro, ancorada no "total acordo de ideias que existia entre

\footnotetext{
${ }^{7}$ A cerimónia de abertura, incluindo o discurso do presidente Roosevelt, foi vista por cerca de seis milhões de pessoas.
} 
ambos sobre o que deveria ser uma representação nacional numa exposição com as características desta" (ACCIAIUOLI, 1998: 85). O edifício apresentava uma base modernizante a nível da estrutura arquitectónica, "abafada" por uma matriz historicista e por manifestações nacionalistas, visíveis no carácter térreo do pavilhão, no seu coroamento com ameias, na simulação do revestimento em pedra, na definição da entrada principal, com uma abertura em arco de volta perfeito, encimada por um escudo nacional, ou mesmo na torre do edifício e no seu prolongamento através de uma arcaria.

A cultura popular exibia-se, mais uma vez, e desde logo, na própria fachada do pavilhão, onde uma monumental vitrine exibia tipos regionais populares: o campino, a lavadeira, a ovarina, etc. Contando praticamente com a mesma equipa de colaboradores de 1937, a sala do "Turismo e Arte Popular" contava, nas paredes, com nichos escavados, preenchidos com bonecas vestidas com trajes regionais; Thomás de Mello fizera um conjunto primoroso de miniaturas dos usos e haveres populares, por regiões. Existiam ainda exemplares de artes tradicionais, como trabalhos têxteis do Entre-Douro-e-Minho; trabalhos em madeira, em estanho e em cobre; rendas de Peniche, Vila do Conde e Niza; bordados de Guimarães e Castelo Branco; cerâmica de Estremoz e peças em barro e vime.

Desta forma, numa exposição internacional subordinada à temática do futuro, Ferro e seus colaboradores colocam a tónica da participação nacional "[in] our strength [which] is above everything, spiritual", corporizada num pavilhão "purposely innocent and lyric", com Portugal assumindo-se em termos essencialmente históricos: "There are undoubtedly richer and stronger Nations [...] but there is certainly none that [...] more contributed to the development of the World!" (COSTA, 1939, s/p).

Realizada praticamente na mesma altura da de Nova Iorque, a Exposição de S. Francisco, a Golden Gate International Exposition ${ }^{8}$, que recebeu cerca de 17 milhões de visitantes, possibilitava a Portugal continuar a sua embaixada de propaganda do país no continente e entre a colónia portuguesa aí residente, aproveitando a presença da equipa de artistas do SPN em solo americano.

\footnotetext{
${ }^{8}$ Abriu as suas portas a 18 de Fevereiro de 1939 e encerrou a 29 de Setembro de 1939.
} 
De acordo com a revista Ocidente, a exposição tinha "por objectivo celebrar o passado das nações que contribuíram para a descoberta da costa do Pacífico" ${ }^{\prime \prime}$. Para o local do certame construiu-se uma ilha na baía de S. Francisco - a ilha do Tesouro.

Aqui, o stand português foi igualmente obra de Jorge Segurado. Nele, o que mais ressalta ao primeiro olhar é a feição tradicionalista da sua fachada, lembrando uma igreja românica do norte do país, no seu aspecto atarracado, na solidez da construção, no forte enraizamento no terreno. Os aspectos arquitectónicos são claramente de feição nacionalista, com a entrada aberta com um arco de volta perfeita, encimado por um escudo ladeado por uma esfera armilar e por uma cruz, com a palavra PORTUGAL a rematar o conjunto. Parece ter-se verificado um verdadeiro retorno formal à Exposição de Sevilha de 1929.

Ferro deixa de lado, no seu discurso visual, o modernismo suavizado das exposições anteriores e apresenta um ideário plenamente tradicional, fazendo a apologia do "lar da alma portuguesa", numa miniaturização do país na apresentação dele feita.

E, assim, mais uma vez a cultura popular se encontra em relevo: peças de arte popular, em particular trajes regionais, bordados da Madeira, peças de filigrana.

Uma vez assegurada a neutralidade da Espanha no conflito mundial iniciado em 1939, afastadas de vez as tentações espanholas de entrada no conflito ao lado do Eixo, e num momento em que se verifica uma reaproximação dos dois países, com a assinatura do Pacto Ibérico, Portugal fez-se representar no país vizinho com uma série de exposições de arte popular portuguesa. Com efeito, e como se reporta na Ocidente, "em verdade não há melhor embaixada num certame internacional ou no seio de nação diferente, por mais próxima que seja, do que a exposição ou prova demonstrativa das artes ricas e policrómicas do povo" ${ }^{10}$.

Assim, nas salas do Mercado Nacional de la Artesania Española, em Madrid, entre Abril e Maio de 1943, o SPN orquestrou uma exposição de arte popular, cuja organização esteve a cargo de Francisco Lage, de Thomás de Mello e Jorge Segurado.

No ano seguinte, na Feira Anual de Sevilha, o Secretariado apresentou uma Caseta de Portugal, instalada na principal avenida do certame. A Panorama apresenta

\footnotetext{
${ }^{9}$ Ocidente, n‥ 12, 04.1939, p. 172.

${ }^{10}$ Ocidente, no. 73, 04.1944, p. 131.
} 
um artigo sobre esta presença portuguesa, descrevendo a Caseta como expondo, no exterior, "a simples e serena arquitectura da casa rústica portuguesa: beiral, janela de caixilhos sóbrios e varanda de ferro forjado. No interior, o clássico ambiente das nossas casas provinciais, mas com um recheio constituído pelas mais típicas espécies regionais das indústrias e artes populares", com objectos como mantas e bilhas alentejanas, bonecos de Barcelos e de Estremoz - onde se incluem elementos de um presépio, púcaros e cantarinhas enfeitadas, bules, cafeteiras, chávenas com pires e rouxinóis -, miniaturas de barcos, máscaras de chocalheiro, de Meirinhos e de Vale do Porco, Mogadouro, referentes às festa de Inverno do nordeste transmontano, colchas de linhas bordadas a seda de Castelo Branco, "[n]uma síntese brilhante, embora modesta, da nossa terra, da nossa vida e dos nossos costumes" ${ }^{11}$. Em simultâneo, instalada no edifício do consulado português encontrava-se em exibição a Exposição de Arte Popular Portuguesa, que depois se repetiu em Valência, na tradicional Feira de Amostras que ali se realizou, nesse mesmo ano.

Nestas mostras de arte popular, a enfâse volta-se para o aspecto estético e decorativo, como sempre: “Como convém ao 'clima' espiritual destas lições de arte do povo, que nunca podem ter a rigidez de museu, os objectos obedecem mais à disposição decorativa de evocações de vida, que ao estudo directo das coisas" ${ }^{12}$.

Os objectivos desta participação em terras espanholas são claros: pelo uso das tradições demóticas portuguesas, procura-se ilustrar a especificidade de Portugal, a sua singularidade, clarificando o carácter português, ao apresentar a nação como poética e lírica, por oposição aos espanhóis, caracterizados pelo dramatismo e intensidade.

Concluindo, pode afirmar-se que a cultura popular se apresenta, na versão "ferrista", como o substrato sobre o qual repousa a identidade nacional, demonstrando a singularidade da pátria portuguesa e evocando um povo de tradições remotas e quase atemporais, que vive em irmandade com a natureza, desligado dos conflitos e clivagens socioeconómicos; em simultâneo, uma Nação onde estas tradições imemoriais são vividas ainda no presente, de forma entusiasta. O passado

\footnotetext{
${ }^{11}$ Panorama, no. 21, 06.1944, s/p.

12 Ocidente, no. 73, 04.1944, p. 131.
} 
assume-se, pois, como algo que marca o presente e que estabelece o futuro, isto é, um exemplo a ser seguido, cunhado por um valor de autenticidade. A promoção da "cultura popular" terá assim funcionado neste período como o "alicerce duma cultura nacional de consenso" (BRANCO, 1999: 44).

\section{FONTES E REFERÊNCIAS BIBLIOGRÁFICAS}

ACCIAIUOLI, Margarida, 1991 - Os Anos 40 em Portugal. O País, o Regime e as Artes. "Restauração" e "Celebração". Tese de Doutoramento apresentada à Faculdade de Ciências Sociais e Humanas da Universidade Nova de Lisboa.

ACCIAIUOLI, Margarida, 1998 - Exposições do Estado Novo: 1934-1940. Lisboa: Livros Horizonte.

ALVES, Vera Marques, 2007 - Camponeses estetas no Estado Novo: Arte Popular e Nação na Política Folclorista do Secretariado da Propaganda Nacional. Lisboa: ISCTE. Tese de Doutoramento apresentada à Universidade Nova de Lisboa.

ANDERSON, Benedict, 2005 - Comunidades Imaginadas. Reflexões sobre a Origem e Expansão do Nacionalismo. Lisboa: Edições 70.

BRANCO, Jorge Freitas, 1999 - "A fluidez dos limites: Discurso Etnográfico e Movimento Folclórico em Portugal”. Etnográfica, vol. III, №. 1, p. 23-48.

CHANDLER, Arthur, 1990 - "Paris 1937. Exposition Internationale des Arts et Techniques dans la Vie Moderne" in FINDLING, John, PELLE, Kimberly (ed.) - Historical Dictionary of World's Fairs and Expositions. 1851-1988. Nova lorque: Greenwood Press, p. 283-290.

COSTA, Marques da (org.), 1939 - Portugal in New York World's Fair. Lisboa: SPN. FERRO, António, 1949 - Panorama dos Centenários (1140-1640-1940). Lisboa: SNI. GELLNER, Ernest, 1993 - Nações e Nacionalismo. Lisboa: Gradiva.

HANDLER, Richard, 1984 - "On sociocultural discontinuity: nationalism and cultural objectification in Quebec". Current Anthropology, vol. 25, no. 1, p. 55-71.

HOBSBAWM, Eric, RANGER, Terence, 1997 - A invenção das tradições. São Paulo: Paz e Terra. 
LÖFGREN, Orvar, 1989 - "The nationalization of culture", p. 1-27 (artigo cedido pelo autor).

MARTINS, Rui Cardoso, 1996 - Exposições Universais: Nova York 1939. Lisboa: Edição Lisboa Expo 98.

Ocidente no. 12, 04.1939, p. 172.

Ocidente, no. 33, 12.1940, p. 322, 431 e 434.

Ocidente, №. 73, 04.1944, p. 131.

OLIVEIRA, Rosa Neves de, 1998 - Paris 1937. Lisboa: Edição Lisboa Expo 98.

“O Pavilhão de Portugal na Exposição Internacional de Paris de 1937". Revista Oficial do Sindicato Nacional de Arquitectos, №. 1, 1938, p. 21.

Panorama, no. 21, 06.1944, s/p.

PAULO, Heloísa, 1994 - Estado Novo e propaganda em Portugal e no Brasil. O SPN/SNI e o DIP. Coimbra: Minerva.

PINA, Paulo, 1988 - "O Consulado de António Ferro". Portugal: o Turismo no século XX. Lisboa: Lucidus, p. 85-106.

“Portugal em Barcelona". Diário de Notícias, 04.06.1929, p. 1.

ROSMANINHO, Nuno, 2010 - “Arte Nacional: Conceito e Funcionalidade" in RIBEIRO, Maria Manuela Tavares (coord.) - Outros Combates pela História. Coimbra: Imprensa da Universidade de Coimbra, p. 521-527.

SNI, 1948 - Museu de Arte Popular. Lisboa: SNI.

SNI, 1955 - Legislação (Contém o Regulamento e Programa dos Concursos). Lisboa: Imprensa Nacional.

STOKLUND, Bjarne, 1999 - "How the Peasant House Became a National Symbol. A Chapter in the History of Museums and Nation-Building". Ethnologia Europaea, vol. 29 , p. $5-18$.

THIESSE, Anne-Marie, 2000 - A criação das identidades nacionais. Lisboa: Temas e Debates.

“Vida". Diário de Notícias, 07.05. 1932, p. 1. 